\title{
Diabetic foot workshop: Improving technical and educational skills for nurses
}

\author{
Maryam Aalaa ${ }^{1}$, Mahnaz Sanjari², Samimeh Shahbazi ${ }^{2}$, Zahra Shayeganmehr ${ }^{2}$, Maryam Abooeirad ${ }^{2}$, \\ Mohammad Reza Amini², Hossien Adibi², Neda Mehrdad ${ }^{2,3 *}$
}

\begin{abstract}
Diabetes mellitus as one of the most common metabolic disorders has some complications, one of the main ones is diabetic foot (DF). Appropriate care and education prevents $85 \%$ of diabetic foot amputations. An ideal management to prevent and treat diabetic foot necessitates a close collaboration between the health team members and the diabetic patient. Therefore, improving nurses' knowledge about DF care and advancement in the quality of care provided by the nurses could significantly improve diabetic foot prevention and management. Therefore, the aim of DF workshop was to improve technical and educational skills of the nurses to prevent and manage diabetic foot. Considering the vital role of the nurses in providing DF care, EMRI decided to conduct Diabetic foot workshop for them. The following five steps were designed for the 14 coordinating sessions in the workshop: Goals definition, deciding about attendees, location selection, creating agenda, and developing a follow-up plan. "Diabetic Foot Workshop for Nurses" provides appropriate training to DF nurses at the national level; and combining theory and practice in this workshop not only increases nurses' knowledge, but also improves their skills in the field of the diabetic foot. Providing education and care to patients by DF nurse specialists instead of general nurses could be an important output of this workshop, which may lead to DF prevention and amputation decrease in the long term.
\end{abstract}

Keywords: Diabetic foot, Nurse, Workshop

Copyright $\odot$ Iran University of Medical Sciences

Cite this article as: Aalaa M, Sanjari M, Shahbazi S, Shayeganmehr Z, Abooeirad M, Amini MR, Adibi H, Mehrdad N. Diabetic foot workshop: improving technical and educational skills for nurses. Med J Islam Repub Iran. 2017 (01 Feb);31:8. https://doi.org/10.18869/mjiri.31.8

\section{Introduction}

Diabetes mellitus (DM) as one of the most important and common metabolic disorders (1) has some complications. Foot ulcer is one of the main complications; $15 \%$ of diabetics develop foot ulcers in their lifetime, and of them, $15-20 \%$ will need amputation (2). In other words, in diabetic patients, diabetic foot ulcer is considered the most common cause of hospitalization (3). However, appropriate care and education prevents $85 \%$ of diabetic foot amputations (4). An ideal management to prevent and treat diabetic foot involves regular perception of foot, determining the at- risk foot, patients and healthcare staffs' education, appropriate foot coverage and early treatment

\section{Corresponding author:Dr Neda Mehrdad,nmehrdad@tums.ac.ir}

1. Diabetes Research Center, Endocrinology and Metabolism Clinical Sciences Institute, Tehran University of Medical Sciences, Tehran, Iran.

2. Endocrinology and Metabolism Research Center, Endocrinology and Metabolism Clinical Sciences Institute, Tehran University of Medical Sciences, Tehran, Iran.

3. Nursing Care Research Center, Iran University of Medical Sciences, Tehran, Iran of any foot problem (5). To achieve the best outcome, a close collaboration among the healthcare team members and diabetic patients is necessary. Clearly, progress in the quality of care provided by a nurse as one of the members of the diabetes care team could significantly improve diabetic foot prevention and management (6). Moreover, a diabetic foot specialist nurse should be trained in DFU beyond basic nursing education (7). Thus, she could take part in administering all diabetic foot care steps including educational interventions, screening high-risk patients and providing health care (8).

\section{$\uparrow$ What is "already known" in this topic:}

Improving nurses' knowledge about diabetic foot care significantly improves diabetic foot prevention and management. A diabetic foot specialist nurse should be trained in educational interventions, screening high-risk patients and providing health care.

$\rightarrow$ What this article adds:

As a result of 14 coordinating sessions in 11 workshops across the country (Iran), goals definition, deciding about attendees, location selection, creating agenda, and developing a follow-up plan were settled. The workshop provided appropriate training to DF nurses at the national level. 
Nurses' Role in Diabetic Foot Prevention and Management

The American Diabetes Association (ADA) has recommended a protocol in the Diabetic Foot prevention and management in which a multidisciplinary team approach is signified (9). Advantages of this approach include preventing diabetes complications and decreasing amputation rates, which have been suggested in several studies (1016). Nurses, as the largest healthcare group who engage in various levels of health (17), and as one of the most important members in the healthcare team, can positively influence diabetic foot prevention and wound healing outcomes by promoting, collaborating and participating in interprofessional healthcare team efforts (18). A diabetes nurse specialist should detect any skin changes and foot sensation, foot care and dressing and should utilize novel technology. In rehabilitation, the nurses have a special role in helping the patients undergo a diabetic foot ulcer management or amputation. The existing data reveal that patient education may decrease diabetic foot ulcers and amputations. Improving the knowledge and behavior of diabetics in the field of diabetic foot may be positively influenced by providing education to the patients in the short term (19).

Considering the fact that nurses are members of diabetic foot care team in Iran, providing diabetic patient education to prevent and manage diabetic foot is one of the responsibilities of the nurses. However, no specific courses or workshops in this field are offered to the nurses to update their knowledge. However, there is a need for such courses because diabetes nurses play an important role in DF prevention and management. Accordingly, Endocrinology and Metabolism Research Institute (EMRI) of Tehran University of Medical Sciences (TUMS), as an institute collaborating with WHO for research and education on management of diabetes, organizes diabetic foot training courses for the nurses and physicians, conducts joint projects, develops therapeutic and research specialist clinics and establishes networks.

\section{Diabetic Foot Workshop for Nurses}

Considering the important role of nurses in the DF care team, EMRI established

Diabetic foot workshops for the nurses. The following five steps were considered in the workshops (20-21).

\section{Step 1: Goals Definition}

The three sessions on brainstorming and lecturers helped the nurses to share their practical work experience with each other and set goals and objectives of the workshop. Accordingly, the course objectives were as follows:

1. To provide the knowledge and skills in evaluating patients suffering from diabetic foot

- To develop a patient care plan focusing on multidisciplinary approaches

Step 2: Deciding about Attendees

Key attendees of the Diabetic foot workshop were registered nurses who had obtained the certificate of Ministry of health $(\mathrm{MOH})$ in Iran and worked in Diabetes clinics or hospitals' internal wards and were interested to complete their experiences in the field of Diabetic foot.

Step 3: Location Selection

According to the number of attendees of the workshop (30 attendees) and the logistics and practical details of the agenda (small group activity), the location had to be Ushaped, where everyone could be able to see the facilitator, other participants and the visual aids.

\section{Step 4: Creating Agenda}

After setting the primary objectives and finding the exact number of attendees, the scientific committee started to develop the outline of the means to achieve the workshop's goals. In this regard, 11 sessions were held to create a list of main points to discuss. The coach's team as a multidisciplinary team focused on different points of view around DF main points. This program was designed according to the needs of those nurses who were the members in diabetic foot care team. Therefore, the main points of this interactive workshop consisted of the epidemiology of diabetic foot. In the second step, according to the nurse care plan, nurses used different DF assessment tools (60 seconds form, Michigan and UK questionnaires) to practice assessing patients suffering from diabetic foot. At the end of this phase, participants prepared a list of the patient's problem using these tools. They learned this concept with more details in role- play. According to the patient problem list, nurses should provide care plans and use the diagnosis to train patients to have self-care for their diabetic foot with and without ulcers. Then nurses should evaluate the patients' thoughts. In the next section, participants learned the main aspects of DF management, especially selecting the proper dressing and way of dressing to prevent amputation. The final section was devoted to diabetic foot ulcer home care and rehabilitation. Nurses were expected to complete the care plan by preparing patient discharge program.

Handouts of slides, which were presented during the workshop and Diabetic foot assessment sheet including UK, Michigan, 60 Seconds Forms to have a practical education in DF assessment, and support materials were given to the participants. To have an understanding about the real experience of DF, the participants were asked to complete the form of 60 seconds DF assessment.

Each lecture was related to the diabetic foot prevention, management, rehabilitation followed by a team work activity (including case presentation, educational film, group discussion and visual demonstration), in which participants were divided into a small group with five members and actively discussed the matter and found the best answers to the educational case questions or educational films' questions. The facilitators took part in team works and assessed the participants.

Active group discussions on specific topics were introduced at the end of the workshop during which individuals were allowed to ask their questions on the related issues.

Step 5: Developing a Follow-up Plan

In this step, a questionnaire was given to the nurses at the 
end of the event, giving them the opportunity to share their opinions about the workshop. Moreover, we created a virtual group in Telegram where we kept all participants informed about what occurred after the workshop.

\section{Conclusion}

Taking into account the importance of professional education in this field and considering the need of DF healthcare team members who work in diabetic foot clinics, Diabetic Foot Workshop Organizers in EMRI conduct DF workshops for nurses at the national level every other month in various provinces, as these workshops provide appropriate training DF nurse.

International Diabetes Federation (2015 to 2017) has recognized this workshop.

We have held 11 workshops in the North (2), South (3), East (1), West (1) and Center (4) of Iran Since August 2014.

Combining theory and practice in this workshop not only increases the nurses' knowledge, but also improves their skills in assessment and patient follow-up in the field of diabetic foot. One of the most important implications of this workshop could be providing proper training to DF nurse specialists, which could lead to foot ulcer prevention and amputation decrease in the long term.

\section{Acknowledgements}

Endocrinology and Metabolism Research Institute (EMRI) of Tehran University of Medical Sciences have supported this project. We gratefully acknowledge the substantial contribution of all scientific and executive personals of this institution.

\section{References}

1. William G, Pickup JC. Introduction to diabetes. In: Handbook of Diabetes, 2nd edn. Oxford: Blackwell, 1999:2-4.

2. Larijani B, Forouzandeh F. Diabetic foot disorders. Iran J Diabetes and Lipid Disord 2003; 2(2):103-93

3. Steed DL, Donohoe D, Webster MW, Lindsley L. Diabetic Ulcer Study Group. Effect of extensive debridement and treatment on the healing of DFUs. J Am CoIlSurg 1996;183:61-4.

4. Tabatabaei-Malazy O, Khatib O. Prevention and public approach to diabetic foot. Iranian J of Diabetes \& Lipid Disorders 2007;7(2):123133.

5. International Working Group on the diabetic foot: International Diabetes Federation Report: International Diabetes Federation. http://www.idf. org/webdata/docs/Diabetes_and_foot.pdf. (Updated: 2000).

6. Spollett CR. Preventing amputations in diabetic populations. Nursing Clinics of North America 1998;33:629-41.

7. Gray M, Ratliff C, Mawyer R. A brief history of advanced practice nursing and its implications for WOC advanced nursing practice. J
Wound Ostomy Continence Nurs 2000;27(1):48-54

8. Amirmohseni L, Nasiri M. The Important Role of Specialist Nurse in the Improvement of Patients With Diabetic Foot Ulcer: Letter to the Editor . Jentashapir J Health Res 2014 October;5(5):e23226.

9. American Diabetes Association (ADA): Standards of medical care in diabetes. Diabetes Care 2010;33(1):S38.

10. Aydin K, Isildak M, Karakaya J, Gürlek A. Change in amputation predictors in diabetic foot disease: effect of multidisciplinary approach Endocrine 2010;38(1):87-92.

11. Hamonet J, Verdié-Kessler C, Daviet JC, Denes E, Nguyen-Hoang $\mathrm{CL}$, Salle JY, et al. Evaluation of a multidisciplinary consultation of diabetic foot. Ann Phys Rehabil Med 2010;53(5):306-318.

12. Muller IS, De Grauw WJ, Van Gerwen WH, Bartelink ML, van Den Hoogen HJ, Rutten GE. Foot ulceration and lower limb amputation in type 2 diabetic patients in Dutch primary health care. Diabetes Care 2002;25(3):570-574.

13. Larsson J, Apelqvist J, Agardh CD, Stenström A. Decreasing incidence of major amputation in diabetic patients: a consequence of a multidisciplinary foot care team approach? Diabetes Care 1995;12(9):770776.

14. Apelqvist J, Larsson J. What is the most effective way to reduce incidence of amputation in the diabetic foot? Diabetes Metab Res Rev 2000;16: S75-S83.

15. Gottrup F: Management of the diabetic foot: surgical and organizational aspects. HormMetab Res 2005;37:69-75.

16. Calle-Pascual AL, Garcia-Torre N, Moraga I, Diaz JA, Duran A, Moñux G, et al. Epidemiology of non-traumatic lower-extremity amputation in Area 7,Madrid, between 1989 and 1999. Diabetes Care 2001;24:1686-1689.

17. Aalaa M, Malazy OT, Sanjari M, Peimani M, Mohajeri-Tehrani M. Nurses' role in diabetic foot prevention and care; a review. J Diabetes Metab Disord 2012 Nov 21;11(1):24.

18. Seaman, S: The role of nurse specialist in the care of patients with diabetic foot ulcers. Foot Ankle Int 2005;26(1):19-26.

19. Valk GD1, Kriegsman DM, Assendelft WJ. Patient education for preventing diabetic foot ulceration. Cochrane Database Syst Rev 2001;(4): CD001488.

20. Steinert Y, Boillat M, Meterissian S, Liben S, McLeod P. Developing successful workshops: a workshop for educators. Medical Teacher 2008; 30(3):328-30.

21. Planning a Workshop, Organizing and Running a Successful Event available at: https://www. mindtools.com/pages/article/Planning AWorkshop.htm. 